\title{
HORMONE REPLACEMENT THERAPY AND THE RISK OF BREAST CANCER: ASSESSMENT OF THERAPY ACCEPTANCE IN A COHORT OF PREVIOUSLY TREATED BREAST CANCER PATIENTS
}

\author{
Agnaldo Anelli, Daniel L. Gimenez, Aline Porto Rocha, Cíntia Mendonça de Abreu \\ and Helano Carioca Freitas
}

ANELLI A et al. - Hormone replacement therapy and the risk of breast cancer: assessment of therapy acceptance in a cohort of previously treated breast cancer patients. Rev. Hosp. Clín. Fac. Med. S. Paulo 58(2):91-96, 2003.

INTRODUCTION: In the postmenopausal period, an average of $25 \%$ of women will present symptomatic ovarian failure requiring hormonal replacement therapy. Estrogen can relieve vasomotor symptoms. Hormonal replacement therapy is generally not recommended for breast cancer patients due to the potential risk of tumor recurrence. To answer the questions about the safety of hormonal replacement therapy in this subgroup of women, it is necessary to establish the acceptance of treatment.

METHODS: Between September 1998 and February 2001, a cohort of 216 breast cancer patients were asked to complete a questionnaire. All patients had completed their treatment and were informed about survival rates after breast cancer and hormonal replacement therapy.

RESULTS: Among the 216 patients, 134 (62\%) would refuse hormonal replacement therapy. A hundred patients were afraid of relapse (74.6\%). Adjuvant tamoxifen therapy was the only statistically significant variable $(70.3 \%$ versus $29.7 \%$ $\mathrm{p}=0.003)$. Understanding clinical stage $(\mathrm{p}=0.045)$ and type of medical assistance (private versus public , $\mathrm{p}=0.033)$ also seemed to influence the decision. Early stage disease $(\mathrm{p}=0.22)$, type of surgical procedure (radical versus conservative, $\mathrm{p}=0.67)$, adjuvant chemotherapy $(\mathrm{p}=0.082)$ or marital status $(\mathrm{p}=0.98)$ were not statistically significant in decision making. Several patients submitted to adjuvant chemotherapy (41.6\%) would accept hormonal replacement therapy under medical supervision, as did most of advanced clinical stage patients $(58.3 \%$; $=0.022)$.

CONCLUSION: There is a high level of rejection for hormonal replacement therapy among breast cancer patients when current data on tumor cure rates, and potential risks of estrogen use is available. Adverse effects of tamoxifen in the adjuvant setting may be the reason for refusal of hormonal replacement therapy .

DESCRIPTORS: Breast cancer. Hormone replacement. Tamoxifen.

\section{INTRODUCTION}

Frequent and intense vasomotor symptoms can be responsible for a significant deterioration in the quality of life of postmenopausal women ${ }^{1}$. Hormone replacement therapy (HRT) with estrogen has been used for many decades for managing menopausal symptoms and urogenital dysfunction as well as for reducing the morbidity and mortality related to osteoporosis and cardiovascular disease ${ }^{2-6}$. Despite the fact that HRT has demonstrably im-

From the Department of Clinical Oncology of the Câncer Hospital, São Paulo/SP and Department of Clinical Oncology of the Brasil Hospital, Santo André/SP. Received for publication on July 03, 2002. proved the quality of life in healthy postmenopausal women; few observational studies ${ }^{7-10}$ have approached this therapy in breast cancer treated patients, and none of them have observed either increased disease recurrence or mortality.

Early detection and improved therapies have shown a positive effect on life expectancy in breast cancer pa- 
tients. As overall and disease- free survival improves, quality of life becomes more important, mostly in those patients who have low- risk breast cancer and experience menopausal symptoms earlier than expected due to antineoplastic treatment.

Based on observational studies ${ }^{11-}$ ${ }^{14}$ reporting a small, but increased risk of breast cancer, HRT is generally not recommended for breast cancer patients succesfully treated, since its effects on the risk of tumor recurrence remains uncertain.

On the other hand, an increasing number of younger patients, who have completed treatment for low- risk breast cancer, will face many years of estrogen deficiency and impaired quality of life. These patients are therefore potential candidates for HRT, since death from nonneoplastic conditions is common among node-negative breast cancer survivors ${ }^{15}$. In the1997's consensus conference about treatment of estrogen deficiency symptoms in women surviving breast cancer, there was an agreement upon the need to conduct trials to evaluate HRT in selected groups of patients ${ }^{16}$. Thus, we have conducted this study to analyze the acceptance of HRT in patients previously treated for breast cancer.

\section{METHODS}

Between September, 1998 and February, 2001; 216 women treated for breast cancer were interviewed. All patients have completed their treatment and were in the follow-up period. Eligibility criteria included histological diagnosis of breast cancer; female sex; completion of breast cancer treatment (surgery, chemotherapy and hormonal therapy); no clinical or radiological evidence of metastatic disease and 18 years of age or older. After signing the informed consent, all patients received three cards with the following informa- tion: clinical menopause symptoms, benefits of HRT, cure rates for early stage breast cancer, HRT and breast cancer risk, data on relationship between nodal stage and risk of recurrence, and a literature overview on HRT and breast cancer. A questionnaire was then applied by the research nurse. The patients were questioned about use of HRT at the time of the study, presence of menopause symptoms and related morbidities (cardiovascular diseases, bone fractures), tumor's clinical stage, previous use of hormones and acceptance of HRT. Statistical analyses were performed by univariate and multivariate logistic regression models to evaluate the relationship concerning HRT acceptance, as well as the independent variables. The study was approved by the internal Institutional Review Board.

\section{RESULTS}

All patients had completed their treatment and were informed about survival rates after breast cancer and
HRT. Patients' characteristics and results are shown in table 1.

Among the 216 patients, 134 (62\%) refused HRT. The main reason was the fear of relapse $(74.6 \%)$. The use of adjuvant tamoxifen citrate therapy was the only statistically significant variable (70.3\% versus $29.7 \%$; $\mathrm{p}=.003 \log$ rank). Refusal was more pronounced among patients who did not know their clinical stage when compared to those who did know (78.6\% versus $59.6 \%$; $=0.045 \log$ rank). Type of medical assistance (private versus public, $68.3 \%$ versus $54.1 \%$, respectively; $\mathrm{p}=0.033 \log$ rank) also seemed to influence the decision.

The majority of patients had early stage disease $(75.9 \%)$, and we observed a tendency to accept HRT among those with advanced stage, although without statistical significance (58.3\% versus $37.8 \%$; $\mathrm{p}=0.22 \log$ rank). Type of surgical procedure (radical mastectomy versus conservative therapies, $\mathrm{p}=0.67 \log$ rank), adjuvant chemotherapy ( $\mathrm{p}=0.082$ log rank) or marital status ( $\mathrm{p}=0.98$ log rank) were also not statistically significant in the

Table 1 - Patients characteristics and acceptance of hormonal replacement therapy.

\begin{tabular}{|c|c|c|c|}
\hline & \multicolumn{2}{|c|}{ Hormonal Replacement Therapy. } & \multirow[t]{2}{*}{$\mathrm{p}$ value } \\
\hline & Yes & No & \\
\hline \multicolumn{4}{|l|}{ Prior treatment } \\
\hline Surgery & & & .678 \\
\hline Radical mastectomy & 38 & 66 & \\
\hline Conservative & 44 & 68 & \\
\hline Chemotherapy & & & .082 \\
\hline Yes & 64 & 90 & \\
\hline No & 18 & 44 & \\
\hline Hormone therapy (adjuvant) & & & .003 \\
\hline Yes & 38 & 90 & \\
\hline No & 44 & 44 & \\
\hline Hormone therapy (others) & & & .035 \\
\hline Yes & 46 & 80 & \\
\hline No & 36 & 48 & \\
\hline Type of health ensurance & & & .033 \\
\hline Public & 44 & 52 & \\
\hline Private & 38 & 82 & \\
\hline Knowledge of Clinical Stage & & & .045 \\
\hline Yes & 76 & 112 & \\
\hline No & 6 & 22 & \\
\hline Clinical Stage & & & .022 \\
\hline Inicial & 62 & 102 & \\
\hline Advanced & 14 & 10 & \\
\hline Unknown & 6 & 22 & \\
\hline
\end{tabular}


decision-making process. Previous hormone therapy was only marginally significant in refusal. Hormones were used as contraceptives (24.1\%), treatment for irregular menses $(5.6 \%)$, and endometriosis $(1.9 \%)$. Twenty-four percent of women ignored the reasons for its use. Among the 126 users, $63.5 \%$ would not accept HRT compared to $57.1 \%$ of non-users $(\mathrm{p}=0.35$ $\log$ rank).

\section{DISCUSSION}

Our study has analyzed the acceptance of HRT among women who have completed their treatment for breast cancer. This is a subgroup of women in which menopause symptoms can begin earlier in life due to treatment induced ovarian failure, and will be exposed to the deleterious effects of hormone deprivation, since HRT is generally not indicated. Although the majority of the patients analyzed in this study were afraid that HRT might lead to cancer recurrence, some of them (38\%) would accept such therapy to control menopause symptoms, and late effects like osteoporosis. The fact that patients with advanced disease would consider taking HRT seems paradoxical. One could say that once the disease was advanced, it could not grow worse with the use of HRT, and these patients were probably more concerned about quality of life rather than survival extension. One of the survey's end-points was to analyze if the type of breast cancer treatment would influence the acceptance of HRT. The survey results suggest that previous hormonal treatment, specially adjuvant tamoxifen citrate, affects patients' attitudes toward HRT. The statistically significant impact that previous use of tamoxifen citrate had on acceptance of HRT may be associated to some of its side effects and duration of treatment, during which patients were reminded most of the time that they were taking a hormonal blocker. Few patients had no knowledge about their clinical stage or previous use of any hormonal manipulation, and that may have been the reason for increased refusal among them $(78.6 \% \mathrm{p}=0.045$ and $100 \% \mathrm{p}=$ $0.035 \%$ log rank; respectively). The absolute refusal among patients who did not know about previous exposure to hormones seems to reflect the uncertainty about a possible connection between them and their tumors' development. Hence it is understandable that they would not accept the risks of relapse by using HRT. These findings probably reflect the importance that correct information about disease, and the exposure to potential risk factors has on decision-making among breast cancer patients.

The hypothesis that estrogen is a promoter of breast cancer is based on epidemiological, clinical and experimental studies ${ }^{13,17-19}$. Epidemiological studies have shown a positive association between breast cancer and HRT. The Collaborative Group on Hormonal Factor in Breast Cancer reanalyzed data from 53,865 postmenopausal women, of whom 17,830 (33\%) had used HRT at some time. A relative risk (RR) of having breast cancer of 1.35 $(2 \mathrm{p}=0.00001)$ for those who used HRT for 5 years or longer was found, but cancers diagnosed in women who had ever used HRT tended to be less advanced clinically. The estimated risk of breast cancer increased by $2.3 \%$ $(95 \% \mathrm{CI}=1.1 \%$ to $3.6 \% ; \mathrm{p}=.0002)$ for each year of postmenopausal use of HRT ${ }^{13}$.

In the prospective cohort of more than 120.000 postmenopausal women (The Nurse's Health Study), the relative risks of breast cancer incidence ranged from 1.09 to 1.47 , but the RR of death from breast cancer for current HRT users was 0.76, suggesting that HRT appears to be associated with a greater risk for breast cancer development than for death due to the neoplasia per $s^{2}$.

Although there are some evidences that estrogen could negatively affect breast cancer incidence, HRT did not increase cancer recurrence or mortality when 2755 women diagnosed with invasive breast cancer were analyzed by O'Meara et al. ${ }^{20}$. The relative risks of cancer recurrence, cancer mortality and overall mortality in women who used HRT after breast cancer diagnosis compared to those who did not use it were 0.50 ( $95 \% \mathrm{CI}=0.30$ to 0.85$), 0.34$ $(95 \% \mathrm{CI}=0.13-0.91)$ and $0.48(95 \%$ $\mathrm{CI}=0.29$ to 0.78 ), respectively; suggesting that HRT after breast cancer has no adverse impact on recurrence and mortality.

Since the cause of death among node- negative breast cancer patients is associated with non-neoplastic conditions, HRT could have a positive effect on overall survival.

Nevertheless, based on the results obtained from randomized trials such as HERS trial ${ }^{21}$, which found no overall cardiovascular benefit of HRT in postmenopausal women with stable coronary heart disease (CHD), and the estrogen replacement and atherosclerosis (ERA) trial ${ }^{22}$ showing that HRT did not slow the progression of atherosclerosis in patients with a history of coronary stenosis; the American Heart Association has advised against the use of HRT alone for secondary prevention of cardiovascular disease in postmenopausal women ${ }^{23}$. Selection bias including age of subjects, severity of CHD and "health user" effect may explain the poor outcome observed in the HERS trial. In addition, the EPAT study (Estrogen in the Prevention of Atherosclerosis Trial) have found different results from those of the ERA trial. In this randomized estrogen-placebo trial, the rate of progression of subclinical atherosclerosis was slower in postmenopausal women taking HRT ${ }^{24}$. Probably only the results from the prospective placebo- 
controlled trial (The Women's Health Initiative Study), expected to recruit over 25,000 postmenopausal women will answer the question about the influence of HRT on primary CHD end points and overall mortality ${ }^{25}$.

The observation of an increasing number of women at younger age diagnosed with invasive breast cancer who expected to suffer early treatment induced menopause, have motivated some series of HRT in these subset of patients. Available data indicate that HRT does not seem to adversely affect breast cancer outcome ${ }^{7-10}$. Among 319 women with breast cancer followed prospectively, there was only one breast cancer event in the HRT group against 20 in the control group ${ }^{10}$. A systematic literature review of 11 stud- ies also showed a RR of breast cancer recurrence of $0.82^{26}$.

Patients with breast cancer who were using replacement estrogens at the time of diagnosis experienced reductions in breast cancer mortality ${ }^{2,27}$. HRT does not seem to have an adverse effect on diagnosis and outcome of early-stage invasive breast cancer when treated with conservative surgery and radiation. In addition, previous history of HRT have not been associated with increased risk of contralateral breast cancer or second nonbreast cancer malignancy ${ }^{28}$.

Our results are similar to those found by Vassilopoulo-Sellin et al. ${ }^{29}$ in a cohort of 224 patients where prior treatment, menopausal status, and symptoms affected patients attitudes toward HRT. Most concerns were the menopause-related risk of osteoporosis $(70 \%)$ heart disease $(72 \%)$ and cancer recurrence $(78 \%)$ due to HRT use; although $44 \%$ of menopausal women would consider HRT under medical supervision.

While discussing menopause management, the potential risks of cancer recurrence and benefits of HRT must be taken into account when patients have a history of breast cancer. Most of all, it is necessary to identify patients needs and concerns. Although quality of life could be improved by HRT, that strategy should be considered with caution, in an investigational clinical setting, until a randomized, prospective controlled trial on the impact of HRT in breast cancer patient's survival is available.

\section{RESUMO}

ANELLI A e col. - Terapia de reposição hormonal e o risco de câncer de mama: avaliação de atitudes em pacientes previamente tratadas por câncer de mama. Rev. Hosp. Clín. Fac. Med. S. Paulo 58(2):91-96 2003.

INTRODUÇÃO: Cerca de $25 \%$ das mulheres apresentarão deficiência estrogênica sintomática necessitando terapia de reposição hormonal. A utilização de terapia de reposição hormonal diminui os sintomas vasomotores e outras morbimortalidades. A terapia de reposição hormonal geralmente não é recomendada para as pacientes com câncer de mama, devido o possível aumento no risco de recorrência. Para responder às questões sobre a segurança da terapia de reposição hormonal neste subgrupo de mulheres, é necessário estabelecer a aceitação do tratamento.

MÉTODO: Entre setembro de 1998 e fevereiro de 2001, 216 pacientes foram submetidas a um questionário auto-aplicável. As pacientes haviam encerrado o tratamento antineoplásico e, receberam informações sobre as taxas de sobrevida após câncer de mama e terapia de reposição hormonal.

RESULTADOS: Entre as 216 pacientes, 134(62\%) não fariam terapia de reposição hormonal. Cem pacientes receavam uma recorrência $(74,6 \%)$. Tamoxifeno adjuvante foi a única variável estatisticamente significativa (70,3\% versus $29,7 \% \mathrm{p}=0,003)$. Conhecimento do estádio clínico $(\mathrm{p}=$ 0,045) e tipo de assistência médica (privada versus pública , $\mathrm{p}=0,033$ ) parecem influenciar a decisão. Estádio inicial $(\mathrm{p}=0,22)$, tipo de cirurgia (radical versus conservadora, $\mathrm{p}=0,67$ ), 
quimioterapia adjuvante $(\mathrm{p}=0,082)$ ou estado civil $(\mathrm{p}=0,98)$ não foram estatisticamente significativos. Várias pacientes submetidas à quimioterapia adjuvante $(41,6 \%)$ aceitariam terapia de reposição hormonal sob supervisão médica, assim como a maioria das pa- cientes com doença avançada $(58,3 \%$; $\mathrm{p}=0,022$ ).

DISCUSSÃO: Foi observada uma alta taxa de rejeição à terapia de reposição hormonal entre as pacientes quando informações atualizadas sobre taxas de cura, e potenciais riscos do uso de estrógeno estão disponíveis. Efeitos adversos associados ao tamoxifeno adjuvante poderiam estar relacionados à maior recusa .

DESCRITORES: Câncer. Mama. Reposição hormonal. Tamoxifeno.

\section{REFERENCES}

1. DALY E, GRAY A, BARLOW D et al. - Measuring the impact of menopausal symptoms in quality of life. Br Med J 1993; 307:836-840.

2. GRODSTEIN F, STAMPFER MJ, COLDITZ GA et al. Postmenopausal hormone therapy and mortality. N Engl J Med 1997; 336:1769-1775.

3. FOLSOM AR, MINK PJ, SELLERS TA et al. - Hormonal replacement therapy and morbidity and mortality in a prospective study of postmenopausal women. Am J Public Health 1995, 85:1128-1132.

4. TORGENSON DJ, BELL-SYER SEM - Hormone replacement therapy and prevention of nonvertebral fractures. A metaanalysis of randomized trials. JAMA 2001; 285:2891-2897.

5. WESTENDORP ICD, VELD BA, GROBBE DE et al. - Hormone replacement therapy and peripheral arterial disease. The Rotterdan Study. Arch Intern Med 2000;160:2498-2502.

6. BUSH TL, BARRET-CONNOR E, CRIQUI MH et al. Cardiovascular mortality and noncontraceptive use of estrogen in women: results from the Lipid Research Clinics Program Follow- up Study. Circulation 1987; 75(6):1102-1109.

7. POWLESTJ, HICKISH T, CASEY S et al. - Hormone replacement after breast cancer (letter). Lancet 1993; 342:60-61.

8. DISAIA PJ, ODICINO F, GROSEN EA et al. - Hormone replacement therapy in breast cancer (letter). Lancet 1993; 342:1232.

9. VASSILOPOULOU-SELLIN R, THERIAULT R, KLEIN MJ Estrogen replacement therapy in women with prior diagnosis and treatment for breast cancer. Gynecol Oncol 1997; 65:8993.
10. VASSILOPOULOU-SELLIN R, ASMAR L, HORTOBAGYI GN et al. - Estrogen replacement Therapy after localized breast cancer: Clinical outcome of 319 women followed prospectively. J Clin Oncol1999; 17:1482-1487.

11. COLDITZ GA, HANKINSON SE, HUNTER DJ et al. - The use of estrogen and progestins and the risk of breast cancer in postmenopausal women. N Engl J Med 1995; 332:1589-1593.

12. COLDITZ GA - Relationship between estrogen levels, use of hormone replacement therapy, and breast cancer. J Natl Cancer Inst 1998; 90:814-823.

13. COLABORATIVE group on hormonal factors in breast cancer and hormone replacement therapy - Collaborative reanalysis of data from 51 epidemiological studies of 52,705 women with breast cancer and 108,411 without breast cancer. Lancet 1997; 350:1047-1059.

14. SCHAIRER C, LUBIN J, TROISI R et al. - Menopausal estrogen and estrogen-progestin replacement therapy and breast cancer risk. JAMA 2000;283;485-491.

15. ROSEN PP, GROSHEN S, KINNE DW et al. - Factors influencing prognosis in node-negative breast carcinoma:analysis of 767 T1N0M0/T2NoMo patients with long-term follow-up. J Clin Oncol. 1993; 1:2090-2100.

16. THE hormone foudation, canadian breast cancer research initiative, national cancer institut of canada, et al. - Concensus Statement: Treatment of estrogen deficiency symptoms in women surviving breast cancer. J Clin Endoc Met 1998; 83: 1993-2000.

17. EARLIST breast cancer trialist' collaborative group - Ovarian ablation in early breast cancer: overview of the randomised trials. Lancet 1996; 348:1189-1196. 
18. M LIPPMAN, G BOLAN, K HUFF - The effects of estrogens and antiestrogens on hormone-responsive human breast cancer in long-term tissue culture . Cancer Res 1976; 36: 4595-4601.

19. MOLINARI AM, BONTEMPO P, SCHIAVONE EM et al. Estradiol Induces Functional Inactivation of p53 by Intracellular Redistribution. Cancer Res 2000;60: 2594-2597.

20. O’MEARA ES, ROSSING MA, DALING JR et al. - Hormone replacement theraphy after a diagnosis of breast cancer in relation to recurrence and mortality. J Natl Cancer Inst 2001; 93(10):754-761.

21. HULLEY S, GRADY D, BUSH T et al. - Heart and Estrogen/ progestin Replacement Study (HERS) Research Group Randomized trial of estrogen plus progestin for secondary prevention of coronary heart disease in postmenopausal women. JAMA 1998; 280(7):605-613.

22. HERRINGTON DM, REBOUSSIN DM, BROSNIHAN KB, et al. - Effects of estrogen replacement on the progression of coronary artery atherosclerosis. N Engl J Med 2000; 343:522529 .

23. MOSCA L, COLLINS P, HERRINGTON DM et al. - Hormone replacement therapy and cardiovascular disease: A statement for healthcare professionals from the American Heart Association. Circulation 2001; 104:499-503.
24. HODIS HN, MACK WJ, SHOUPE D et al. - Estrogen in the prevention of atherosclerosis. A randomized, double-blind, placebo-controled trial. Ann Intern Med 2001; 135(11):939953.

25. THE women's health initiative study group - Design of the Women's Health Initiative Clinical Trial and Observational Study. Control Clin Trials 1998; 19:61-109.

26. COL NF, HIROTA LK, ORR RK et al. - Hormone replacement therapy after breast cancer: A systematic review and quantitative assesment of risk. J Clin Oncol 2001; 19:2357-2363.

27. SCHAIRER C, GAIL M, BYRNE C et al. - Estrogen replacement therapy and breast cancer survival in a large screening study. J Natl Cancer Inst 1999; 91:264-270.

28. FOWBLE B, HANLON A, FREEDMAN G et al. - Postmenopausal hormone replacement therapy: Effect on diagnosis ond outcome in early-stage invasive breast cancer treated with conservative surgery and radiation. J Clin Oncol 1999; 19:1680-1688.

29. VASSILOPOULO-SELLIN R, ZOLINSK C - Estrogen replacement therapy in women with breast cancer: A survey of patients attitudes. Am J Med Sci 1992; 342:1232. 